\title{
EFFECTS OF ARTIFICAL SUBSTRATE ON REARING OF MACROBRACHIUM ROSENBERGII POST-LARVAE IN POND NET CAGE
}

\author{
H. Thapa ${ }^{1}$, S. M. Rafiquzzaman ${ }^{1}$, M. M. Rahman ${ }^{2}$ and M. J. Alam ${ }^{\text {* }}$
}

\begin{abstract}
Two experiments were carried out to evaluate the effects of addition of net piece substrates in cages for nursery rearing of freshwater prawn, Macrobrachium rosenbergii post-larvae. In the first experiment, net piece substrates were added with an arrangement to increase the surface area of nursery cages to $50 \%$ and $75 \%$ and compared with cages without any substrate (control). In the second experiment, maintaining surface area increment at $75 \%$ in all cages, the net piece substrates were arranged in three different orientations of horizontal, vertical, and $45^{\circ}$ angle sloping. Experiments were conducted in a pond of Faculty of Fisheries, Bangabandhu Sheikh Mujibur Rahman Agricultural University, Gazipur, Bangladesh for a period of 45 days in June -August of 2015 and 2016. A completely randomized design was followed to assign the treatments with three replications. The $75 \%$ area increment group showed significantly higher $(\mathrm{P}<$ $0.05)$ growth $(1.02 \pm 0.09 \mathrm{~g})$ and survival rate $(79.43 \pm 1.63 \%)$, compared to $50 \%$ area increment $(0.96 \pm 0.05 \mathrm{~g}$ and $75.03 \pm 2.45 \%)$ and control group $(0.79 \pm 0.06 \mathrm{~g}$ and 66.66 $\pm 3.57 \%$ ). The vertically oriented substrate group showed significantly lower growth $0.95 \pm 0.04 \mathrm{~g})$ and survival $(76.33 \pm 1.15 \%)$, compared to the horizontal $(1.06 \pm 0.05$ $\mathrm{g}$ and $77.12 \pm 1.20 \%)$ and sloping $(1.16 \pm 0.10 \mathrm{~g}$ and $79.33 \pm 0.57 \%)$ substrate group. However, there were no differences between horizontal and sloping substrate groups regarding final length, final weight, specific growth rate (SGR), and survival rate except food conversion ratio (FCR). The overall results suggested that modification of net cage nursery structure of $M$. rosenbergii might have significant effects on growth and survival of post-larvae by the manipulation of their behaviour in culture system.
\end{abstract}

Keywords: Net cage nursery, freshwater prawn, behavioural manipulation, growth, survival.

\section{Introduction}

Bangladesh is a riverine country with its vast fisheries resources. Prawn and shrimp production attributes to $3.23 \%$ of the country's total gross domestic production (GDP), and the giant freshwater prawn, Macrobarchium rosenbergii, contributes a significant portion to it (DoF, 2018). M. rosenbergii, which is indigenous to the South and Southeast Asia, together with Northern Australia and the Western Pacific Islands was successfully domesticated in 1960s (Ling, 1969). Since then prawn culture has been increased dramatically in tropical and subtropical regions due to its growing market demand and culture suitability (D’Abramo et al., 1989). However, expansion

\footnotetext{
${ }^{1}$ Department of Fisheries Biology and Aquatic Environment, Bangabandhu Sheikh Mujibur Rahman Agricultural University, Gazipur 1706, Bangladesh; ${ }^{2}$ Institute of Biotechnology and Genetic Engineering, Bangabandhu Sheikh Mujibur Rahman Agricultural University, Gazipur 1706, Bangladesh. *Corresponding author: Email: mjalam@bsmrau.edu.bd
} 
of prawn farming in Southeast Asian countries is limited by several factors, such as the inadequate supply of quality seeds, high production cost, lack of research regarding appropriate research and extension work in technology development and dissemination (Srinivas and Venkatrayalu, 2016).

Nursing of $M$. rosenbergii is a transitional stage where post-larvae (PL) are reared at high densities to juveniles. Before stocking in grow-out ponds, nursing of PLs for 1-2 months have been identified as an essential step to increase survival rate, growth, food conversion efficiency and productivity (Alam, et al., 1997; Alston, 1989; Carvalho-Filho and Mathias, 1998; Cohen, et al., 1981; New and Singholka, 1985; New, 1990). Net cage nursing system is one of the techniques for nursing the PL, and it is gaining popularity due to its practicability and low cost (Beveridge, 2004; Kiyohara, 2006). For example, using a smaller mesh size of net prevents unwanted species' entry (Cuvin-Aralar et al., 2013). Moreover, prawn culture in net cage facilitates easy access, management, and harvest. Besides, net clogging problem can be avoided due to the short nursery period (45-60 days), making net cage nursing of PL more viable. Several studies reported that prawn's benthic and territorialism nature results in heavy growth dependency on a waterbody's two-dimensional area (Cohen et al., 1981; Tidwell et al., 1998). D'Abramo et al. (2006) suggested that the addition of substrate in a pond can provide the prawns with the opportunity to utilize the waterbody's three-dimensional area.

Different types of artificial substrates such as dried tree branches, bamboo pools, gravels, aquatic plants, and shells have been used and proved to improve growth, survival rate and productivity in both indoor and outdoor prawn culture conditions (Mamun et al., 2010; Tidwell et al., 1998). On the other hand, the effects of the substrate's orientation in the prawn PL nursery system are not apparent. Smith and Sandifer (1975) reported that the horizontally placed substrate group showed a higher survival rate than the vertically placed substrate group. In contrast, Tidwell et al. (2002) and Marcus (2002) did not find any significant difference in survival rate or average individual weight of prawn between the horizontal and vertical substrate. No studies have observed the effects of addition and orientation of substrate on the net cageprawn nursing system. We hypothesized that the increase in net cage surface area by adding substrate and substrate's orientation might significantly affect growth, survival rate, and FCR of prawn PL. With this hypothesis, two experiments were carried out to evaluate whether the substrate's addition and orientation in the net cage increase the growth, survival, and FCR of prawn PL.

\section{Materials and Methods}

Both cage nursery experiments were conducted, for a period of 45 days in June - August covering the years of 2015 and 2016, using an existing pond of 10 decimals with an average water depth of $1.7 \mathrm{~m}$ that was located at the pond complex of the Faculty of Fisheries, Bangabandhu Sheikh Mujibur Rahman Agricultural University (BSMRAU), Gazipur. No extra pond management was done except cleaning aquatic weeds manually, fortnight interval liming at a rate of $1 \mathrm{~kg} \mathrm{dec}^{-1}$, and maintaining proper water level by adding or draining. 


\section{Design of the experiment}

Experiment 1: Substrate addition for increasing cage surface area

Under experiment 1 , we initially tested the hypothesis that the net cage area increment using substrate can influence the growth and survival of prawn PL. The experiment consisted of three treatments, i.e. (i) no increase in surface area (control), (ii) $50 \%$ surface area increment of the net cage through the addition of substrate, and (iii) $75 \%$ surface area increment of the net cage through the addition of substrate. The treatments were assigned into a Completely Randomized Design with three replicates for each.

\section{Experiment 2: Orientation of substrate addition}

We performed experiment 2 to test whether the substrate's orientation can influence the growth and survival of prawn PL. There were three treatments, i.e. (i) horizontally placed substrate, $\mathrm{T}_{1}$; (ii) vertically placed substrate, $\mathrm{T}_{2}$; and (iii) 45-degree sloping substrate, $\mathrm{T}_{3}$. In this experiment, $75 \%$ area increment was ensured by adding a substrate for all treatment groups. The treatments were assigned into a Completely Randomized Design with three replicates for each.

\section{Net cage preparation and installation}

The net cage was made of polyethylene net of $1 \mathrm{~mm}$ mesh size. The size of each net cage was $2.44 \mathrm{~m} \times 1.83 \mathrm{~m} \times 1.4 \mathrm{~m}$. As substrate, $2-3 \mathrm{~mm}$ mesh size polyethylene net was used. In case of the $1^{\text {st }}$ experiment, polyethylene nets were cut into pieces to have the desired increase in area and tied with net wall to remain the net pieces hang horizontally. Spaces were kept in between net pieces so that the applied feed could be distributed up to the bottom. In the $2^{\text {nd }}$ experiment, the net cage and the type of substrate material were similar to what we used for experiment 1 . The only exception was the orientation of the substrate. Substrates were placed horizontally, vertically, and with an inclination angle of $45^{\circ}$ according to the experimental design. Cages were installed seven days before stocking of the PL. Only bamboo poles were driven into the pond bottom and used to make the supporting frame for net cages. The upper and lower corners of each cage were fastened with bamboo poles so that the cages remained suspended about $10 \mathrm{~cm}$ above the pond bottom in the water column without touching the pond bottom.

\section{Prawn PL stocking and feeding}

In both experiments, 900 prawn PL individuals were stocked in each cage. Prawn PLs were collected from the Swarnalata Fish Hatchery, Thrishal, Mymensingh. The PLs were transported in oxygenated plastic bags to BSMRAU campus. Upon arrival, the PLs were acclimatized allowing the bags floated in the experimental pond for about half an hour. Initial length $(\mathrm{cm})$ and weight $(\mathrm{g})$ of 100 randomly selected PLs were recorded. The number of PLs were counted in a jar and released into each net cage following the design. A commercial prawn feed (Quality Prawn Feed) with $40 \%$ crude protein, 18\% carbohydrate, $7 \%$ fat, $2 \%$ fiber, $11 \%$ ash, $3.2 \%$ calcium, and $10 \%$ moisture level was provided to the prawn PL throughout the experimental period. Feed was supplied at the rate of $100 \%$ body weight for the first seven days, and after every seven days onward the feed percentage was reduced by $10 \%$. We fed the prawn PL twice a day, half of the ration in the morning and the rest in the evening. 


\section{Data collection}

Prawn PLs were sampled weekly and growth parameters such as length $(\mathrm{cm})$ using measuring scale and weight (g) using an electronic balance of the 15 randomly taken PLs were monitored. At the end of eight weeks days of rearing period, all prawns from each cage were counted to determine survival rate. Final length $(\mathrm{cm})$ and weight $(\mathrm{g})$ of 25 randomly sampled prawns from each net cage were measured using a standard measuring scale and electric balance. The SGR (specific growth rate, $\%$ bw day ${ }^{1}$ ), survival rate from normalized values, and feed conversation ratio (FCR) were determined following the formula below:

i. $\quad \operatorname{SGR}(\%$ bw day- $)=[\ln$ (final weight $)-$ $\ln$ (initial weight) $\times 100] \div$ No. of days of the experiment

ii. Survival rate $(\%)=$ Number of fish stocked $\div$ Number of fish harvested $\times 100$

iii. Feed conversion ratio $(\mathrm{FCR})=$ Feed applied (dry weight) $\div$ Live weight gain

Different physico-chemical parameters of water inside the net cages were recorded weekly. Water temperatures were recorded using a portable digital Celsius thermometer. Dissolved oxygen of water was measured by a portable digital dissolved oxygen (DO) meter (Model: Lutron, PDO-519) on the spot. Measurement of dissolved oxygen was done at each net cage. $\mathrm{pH}$ was measured on the spot using a portable digital $\mathrm{pH}$ meter (Model: sensION pH3 Meter Lab PHM310). Measurement of $\mathrm{pH}$ was done at each cage. Periphyton growth in net cages and substrate surfaces was estimated following the method described by Azim et al. (2001).

\section{Data analysis}

Two-way repeated measure test was used, where treatment account for between-subject variation, and time accounts for withinsubject variation, to test if water quality parameters (temperature, $\mathrm{DO}$, and $\mathrm{pH}$ ) vary among treatments and over the experimental period. To test the effect of substrate addition and orientation in the net cage on prawn final length and weight a one-way nested ANOVA ( $\alpha=0.05)$, using "percent of area increment" as a fixed factor (experiment 1) and "net cage" as a random factor (Krzywinski et al., 2014). For the second experiment, we run the same oneway nested ANOVA using "orientation of substrate" as a fixed factor. To test the effect of substrate addition and orientation on FCR, SGR, and survival rate of prawn, we used three one-way ANOVA $(\alpha=0.05)$. To normalize the survival rate data, we performed an arcsin square root transformation on the percentage data. Tukey's HSD post-hoc test was performed to determine pairwise differences. Assumptions of normality and equality of variance of the data were confirmed by visual inspection of the residuals. All analyses were conducted using IBM SPSS statistics software (Version 24).

\section{Results}

\section{Experiment 1}

The average mean values along with the ranges of different water quality parameters those were recorded during the experimental period are presented in Table 1. There was no significant difference $(\mathrm{P}>0.05)$ in variations of each parameter among the treatments.

There was a significant effect of area increment through the substrate on final 
Table 1. Values (Mean $\pm \mathrm{SE}$ ) and ranges of water quality parameters in different treatments of without substrate $\left(T_{1}\right)$, substrate with $50 \%$ area increment $\left(T_{2}\right)$, and substrate with $75 \%$ area increment $\left(T_{3}\right)$ during the experimental period

\begin{tabular}{lccc}
\hline \multirow{2}{*}{ Water quality parameters } & \multicolumn{3}{c}{ Treatments } \\
\cline { 2 - 4 } & $\mathrm{T}_{1}$ & $\mathrm{~T}_{2}$ & $\mathrm{~T}_{3}$ \\
\hline Temperature $\left({ }^{\circ} \mathrm{C}\right)$ & $30.60^{\mathrm{a}} \pm 1.27$ & $30.64^{\mathrm{a}} \pm 1.25$ & $30.69^{\mathrm{a}} \pm 1.29$ \\
& $(28.3-32.3)$ & $(28.5-32.5)$ & $28.4-32.5)$ \\
Dissolved Oxygen $\left(\mathrm{mg} \mathrm{L}^{-1}\right)$ & $5.38^{\mathrm{a}} \pm 0.30$ & $5.29^{\mathrm{a}} \pm 0.35$ & $5.20^{\mathrm{a}} \pm 0.41$ \\
& $(5.0-5.9)$ & $(4.7-5.8)$ & $(4.5-5.8)$ \\
$\mathrm{pH}$ & $7.28^{\mathrm{a}} \pm 0.42$ & $7.19^{\mathrm{a}} \pm 0.45$ & $7.14^{\mathrm{a}} \pm 0.42$ \\
& $(6.6-7.9)$ & $6.4-7.8)$ & $(6.5-7.8)$ \\
\hline
\end{tabular}

prawn length $(\mathrm{P}=0.02)$ and weight $(\mathrm{P}=0.04)$. In addition, a significant effect of net cage on final length $(\mathrm{P}=0.03)$ and final weight $(\mathrm{P}=$ $0.01)$ of prawn PL was also found. Prawn PL reared in net cage with $75 \%$ area increment and $50 \%$ area increment, showed a similar final length $(\mathrm{P}=0.37$, Table 2). However, treatment with $75 \%$ and $50 \%$ area increment showed significantly higher final length $(\mathrm{P}=0.00$, Table 2) than the control. Treatment with $75 \%$ area increment and 50\% area increment showed $12.39 \%$ and $9.61 \%$ higher final length than the control. Prawn PL showed an increase in final weight with increasing area increment (Table 2).

Prawn PL in the $75 \%$ area increment group showed $6.25 \%$ and $29.11 \%$ higher final weight than $50 \%$ area increment and the control group, respectively ( $\mathrm{P}=0.04$ and $\mathrm{P}<0.001$, respectively). In addition, $50 \%$ area increment group showed significantly higher final weight $(21.5 \%)$ than the control group $(\mathrm{P}=0.008)$. The One-way ANOVAs revealed that increase in net cage area through addition of substrate significantly affected survival rate $(\mathrm{P}=0.003)$, FCR $(\mathrm{P}=0.008)$, and SGR ( $\mathrm{P}$ $=0.01)$. Net cage with $75 \%$ area increment showed the highest survival rate, which was not significantly higher than the $50 \%$ area increment group $(\mathrm{P}=0.06)$. Prawn $\mathrm{PL}$ in $75 \%$ area increment treatment showed 19.15\% higher survival rate $(79.43 \pm 6.05 \%)$ compared to the control group (66.66 $\pm 6.21 \%$, Table 2$)$.

However, there was no significant difference between the survival rate of PL reared in the net cage with $50 \%$ area increment $(75.03 \pm$ $2.45)$ and no area increment $(\mathrm{P}=0.06)$. Net cage with $75 \%$ and $50 \%$ area increment showed significantly higher SGR compared to net cage with no area increment $(75 \%$ area increment vs. no area increment: $\mathrm{P}=0.014,50 \%$ area increment vs. no area increment: $\mathrm{P}=0.03$, Table 2). However, there was no significant difference between net cage with $75 \%$ area increment and 50\% area increment $(\mathrm{P}=0.82)$. The control group showed $7.02 \%$ and $5.30 \%$ less SGR than $75 \%$ and $50 \%$ area increment group, respectively (Table 2). FCR was 35\% lower in $75 \%$ area increment group compared to the control ( $\mathrm{P}=0.007$, Table 2$)$. There was no significant difference in FCR between the control and $50 \%$ area increment group $(\mathrm{P}=0.08)$. No significant difference in FCR between $75 \%$ area increment group and 50\% area increment group $(\mathrm{P}=0.15)$ was found. 
Table 2. Growth parameters (Mean $\pm \mathrm{SE}$ ) of $M$. rosenbergii $\mathrm{PL}$ in different treatments of without substrate $\left(T_{1}\right)$, substrate with $50 \%$ area increment $\left(T_{2}\right)$, and substrate with $75 \%$ area increment $\left(T_{3}\right)$.

\begin{tabular}{lccc}
\hline \multirow{2}{*}{ Growth parameters } & \multicolumn{3}{c}{ Treatments } \\
\cline { 2 - 4 } & $0.95 \pm 0.16^{\mathrm{a}}$ & $0.95 \pm 0.17^{\mathrm{a}}$ & $0.95 \pm 0.15^{\mathrm{a}}$ \\
\hline Initial length $(\mathrm{cm})$ & $4.68 \pm 0.67^{\mathrm{b}}$ & $5.13 \pm 0.64^{\mathrm{a}}$ & $5.26 \pm 0.57^{\mathrm{a}}$ \\
Final length (cm) & $0.02 \pm 0.003^{\mathrm{a}}$ & $0.02 \pm 0.003^{\mathrm{a}}$ & $0.02 \pm 0.003^{\mathrm{a}}$ \\
Initial weight $(\mathrm{g})$ & $0.79 \pm 0.06^{\mathrm{c}}$ & $0.96 \pm 0.05^{\mathrm{b}}$ & $1.02 \pm 0.09^{\mathrm{a}}$ \\
Final weight $(\mathrm{g})$ & $7.54 \pm 0.11^{\mathrm{b}}$ & $7.94 \pm 0.13^{\mathrm{a}}$ & $8.07 \pm 0.19^{\mathrm{a}}$ \\
SGR (\% bw day $\left.{ }^{-1}\right)$ & $66.66 \pm 6.21^{\mathrm{b}}$ & $75.03 \pm 2.45^{\mathrm{a}}$ & $79.43 \pm 6.05^{\mathrm{a}}$ \\
Survival rate $(\%)$ & $2.63 \pm 0.38^{\mathrm{b}}$ & $1.98 \pm 0.33^{\mathrm{ab}}$ & $1.69 \pm 0.16^{\mathrm{a}}$ \\
FCR & & &
\end{tabular}

Mean values with different superscripts letters in the same row indicate significant difference at $5 \%$ level of significance.

About 19genera of phyto-periphytonbelonging to Bacillariophyceae (9), Chlorophyceae (3), Cyanophyceae (5) and Rhodophyceae (1), and five genera of zoo-periphyton belonging to Rotifera (4) and Crustacea (1) were identified as periphyton communities in the surface of net cages during the experiment (Fig. 1). The mean values periphyton (both phyto- and zoo- periphyton) concentration in the treatments $\mathrm{T}_{1}, \mathrm{~T}_{2}$ and $\mathrm{T}_{3}$ were $5091 \pm 1233,4815 \pm 1401$ and $4751 \pm 1432$ units $\mathrm{cm}^{-1}$, respectively. The average weekly variations in periphyton concentrations in different treatments are presented in Fig. 1, which showed a decreasing trend on periphyton concentration over the experimental period.

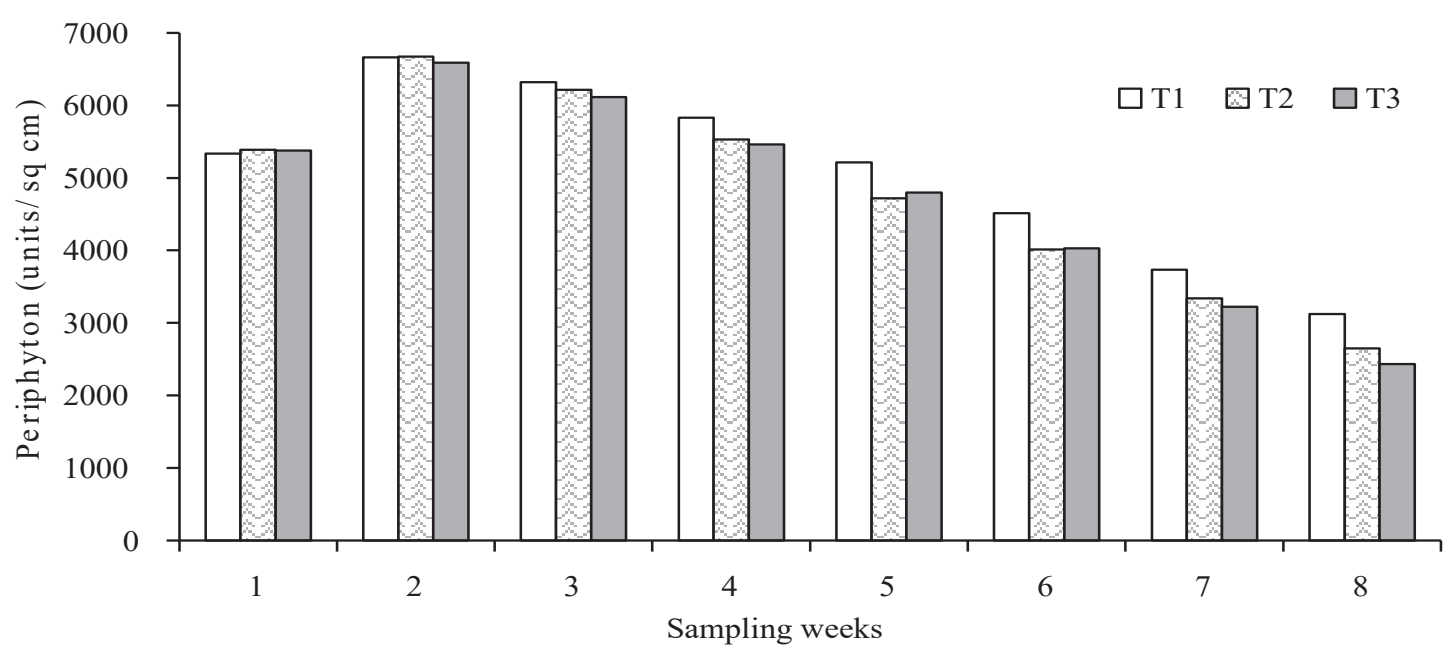

Fig. 1. Growth of periphyton (unit $\mathrm{cm}^{-2}$ ) in three treatments of without substrate $\left(\mathrm{T}_{1}\right)$, substrate with $50 \%$ area increment $\left(T_{2}\right)$, and substrate with $75 \%$ area increment $\left(T_{3}\right)$. 


\section{Experiment 2}

The average mean values and their ranges of different water quality parameters during the experimental period are presented in Table 3 . There was no significant difference $(\mathrm{P}>0.05)$ in variations of each parameter among the treatments.

There was a significant effect of substrate addition in the net cage on prawn's final length $(\mathrm{P}=0.001)$ and weight $(\mathrm{P}=0.001)$. However, no significant effect of net cages on final length $(P=0.91)$ and final weight $(P=0.91)$ of prawn PL was found. The final length of prawn PL in the net cage with the vertically placed substrate was significantly lower compared to the horizontally placed substrate $(4.2 \%, \mathrm{P}=$ $0.03)$ and sloping substrate $(7.2 \%, \mathrm{P}<0.001)$. In contrast, there was no significant difference between a net cage with the horizontally placed substrate and sloping substrate $(\mathrm{P}=$ 0.14 , Table 4). In case of the final weight, the net cage with sloping substrate showed $22.1 \%$ higher final weight $(\mathrm{P}<0.001)$ compared to the horizontal substrate group (Table 4). On the other hand, the horizontal substrate group showed $11.6 \%$ higher final weight than the vertical substrate group $(\mathrm{P}=0.02)$. However, the horizontally placed substrate did not show any significant difference in final weight compared to both vertically placed substrate group $(\mathrm{P}=0.06)$ and sloping substrate group $(\mathrm{P}=0.09)$. There was a significant effect of orientation of substrate on FCR $(\mathrm{P}=0.001)$, SGR $(P=0.002)$, and survival rate $(P=0.02)$ of prawn $\mathrm{PL}$.

Prawn PLs in vertically placed substrate treatment showed significantly higher FCR compared to the treatment with horizontal $(11 \%, P=0.02)$ and sloping substrate $(21.1 \%, P=0.001)$. In addition, horizontal substrate treatment showed significantly higher FCR than sloping substrate treatment (14.6\%, P $=0.01$, Table 4). Prawn PL in vertically placed substrate treatment showed significantly lower SGR than horizontally and sloping substrate treatments $(\mathrm{P}=0.02$ and $\mathrm{P}$ $=0.001$, respectively). However, there was no significant difference in SGR of prawn between horizontal and sloping substrate treatment $(\mathrm{P}=0.06)$. Sloping substrate and horizontally placed substrate showed $5 \%$ and 3\% higher SGR than the vertically placed treatment, respectively (Table 4). Moreover, there was no significant difference

Table 3. Values (Mean \pm SE) and ranges of water quality parameters in different treatments of horizontal $\left(T_{1}\right)$, vertical $\left(T_{2}\right)$ and sloping $\left(T_{3}\right)$ substrate during the experimental period

\section{Water quality parameters}

\begin{tabular}{lc}
\cline { 2 - 2 } & $\mathbf{T}_{1}$ \\
\hline Temperature $\left({ }^{\circ} \mathrm{C}\right)$ & $30.86^{\mathrm{a}} \pm 0.85$
\end{tabular}

$(29.4-32.4)$

Dissolved Oxygen $\left(\mathrm{mg} \mathrm{L}^{-1}\right)$

$\mathrm{pH}$ $5.29^{\mathrm{a}} \pm 0.22$

$(5.0-5.7)$

$7.23^{\mathrm{a}} \pm 0.39$

$(6.4-7.8)$
Treatments

$\begin{array}{cc}\mathbf{T}_{\mathbf{2}} & \mathbf{T}_{\mathbf{3}} \\ 30.86^{\mathrm{a}} \pm 0.87 & 30.87^{\mathrm{a}} \pm 0.85 \\ (29.5-32.4) & 29.4-32.3) \\ 5.27^{\mathrm{a}} \pm 0.25 & 5.27^{\mathrm{a}} \pm 0.21 \\ (4.8-5.6) & (5.0-5.7) \\ 7.22^{\mathrm{a}} \pm 0.38 & 7.24^{\mathrm{a}} \pm 0.40 \\ 6.5-7.7) & (6.4-7.7)\end{array}$


Table 4. Growth parameters (Mean \pm SE) of $M$. rosenbergii $\mathrm{PL}$ in different treatments of horizontal $\left(T_{1}\right)$, vertical $\left(T_{2}\right)$ and sloping $\left(T_{3}\right)$ substrate

\begin{tabular}{lccc}
\hline Growth parameters & \multicolumn{3}{c}{ Treatments } \\
\cline { 2 - 4 } & $\mathbf{T}_{\mathbf{1}}$ & $\mathbf{T}_{\mathbf{2}}$ & $\mathbf{T}_{\mathbf{3}}$ \\
\hline Initial length $(\mathrm{cm})$ & $0.88 \pm 0.12^{\mathrm{a}}$ & $0.88 \pm 0.12^{\mathrm{a}}$ & $0.88 \pm 0.12^{\mathrm{a}}$ \\
Final length $(\mathrm{cm})$ & $5.21 \pm 0.11^{\mathrm{a}}$ & $5.00 \pm 0.09^{\mathrm{b}}$ & $5.36 \pm 0.13^{\mathrm{a}}$ \\
Initial weight $(\mathrm{g})$ & $0.019 \pm 0.01^{\mathrm{a}}$ & $0.019 \pm 0.01^{\mathrm{a}}$ & $0.019 \pm 0.01^{\mathrm{a}}$ \\
Final weight $(\mathrm{g})$ & $1.06 \pm 0.05^{\mathrm{a}}$ & $0.95 \pm 0.04^{\mathrm{b}}$ & $1.16 \pm 0.10^{\mathrm{a}}$ \\
SGR (\% bw day $\left.{ }^{-1}\right)$ & $8.38 \pm 0.07^{\mathrm{a}}$ & $8.15 \pm 0.11^{\mathrm{b}}$ & $8.58 \pm 0.13^{\mathrm{a}}$ \\
Survival rate $(\%)$ & $77.12 \pm 1.20^{\mathrm{a}}$ & $76.33 \pm 1.15^{\mathrm{b}}$ & $79.33 \pm 0.57^{\mathrm{a}}$ \\
FCR & $1.65 \pm 0.06^{\mathrm{b}}$ & $1.77 \pm 0.06^{\mathrm{a}}$ & $1.53 \pm 0.02^{\mathrm{c}}$ \\
\hline
\end{tabular}

Mean values with different superscripts letters in the same row indicate significant at $5 \%$ level of significance.

in the survival rate of prawn PL between horizontal and sloping substrate treatment $(\mathrm{P}$ $=0.9$ ). However, both horizontal and sloping substrate treatment showed a significantly higher survival rate of prawn PL than vertical substrate treatment $(\mathrm{P}=0.03$ and $\mathrm{P}=0.02)$. Sloping substrate treatment showed $4 \%$, and horizontal substrate treatment showed 3\% higher survival rate than the vertical substrate treatment (Table 4).

About22 genera of phyto-periphyton belonging to Bacilla tiphyceae (10), Chlorophyceae (9),
Cyanophyceae (4) and Rhodophyceae (1), and five genera of zoo-periphyton belonging to Rotifera (4) and Crustacea (1) were identified as periphyton communities in the surface of net cages during the experiment. The mean values periphyton concentration in the treatments $T_{1}, T_{2}$ and $T_{3}$ were $5016 \pm$ $1171,5311 \pm 933$ and $5034 \pm 1121$ units $\mathrm{cm}^{-}$ 1 , respectively. The average weekly variations in periphyton concentrations in different treatments are presented in Fig. 2, which showed a decreasing trend on periphyton concentration over the experimental period.

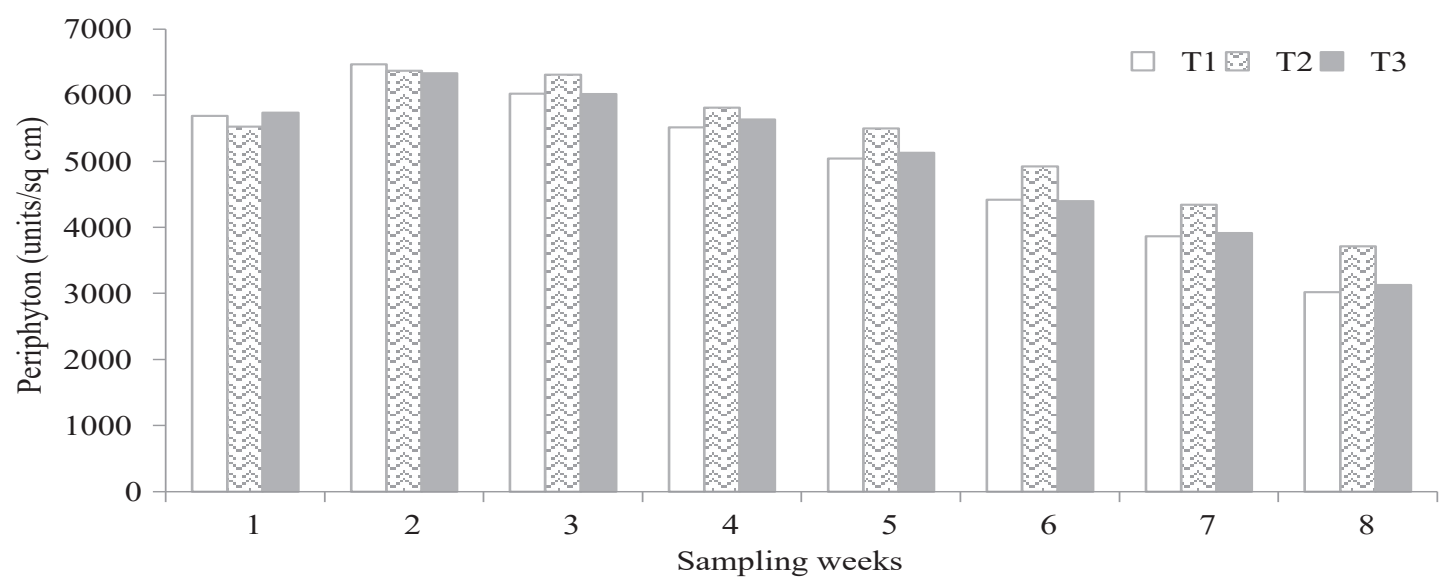

Fig. 2. Growth of periphyton (unit $\mathrm{cm}^{-2}$ ) in three treatments of substrate with horizontal $\left(\mathrm{T}_{1}\right)$, vertical $\left(T_{2}\right)$ and $45^{\circ}$ sloping $\left(T_{3}\right)$ orientation. 


\section{Discussion}

We found that prawn PL showed overall better growth and survival rate with net substrate in the net cage nursery unit. In addition, the substrate placed at a $45^{0}$ of sloping orientation showed better FCR.

Water quality has an immense effect on any aquatic organism. Fish and prawn have more or less the same temperature tolerances, and a temperature range between $26^{\circ} \mathrm{C}$ and $32^{\circ} \mathrm{C}$ is considered suitable for the metabolic activity of $M$. rosenbergii (Boyd and Zimmermann, 2010). Temperature ranges found in both experiments were within the acceptable range. $\mathrm{pH}$ is an important factor that affects survival, growth, moulting, and feeding activities of prawn. $\mathrm{pH}$ levels ranging from 6.2 to 7.4 has been reported suitable for prawn (Chen and Chen, 2003) 48-, 72- and 96-h LC50s (median lethal concentrations, which indicates that the $\mathrm{pH}$ found in the present experiments were within the acceptable limit. Although $M$. rosenbergii can survive the DO level below $2 \mathrm{mgL}^{-1}$, a minimum of $3 \mathrm{mgL}^{-1}$ is needed to be maintained to avoid stress and optimal growth rate (Abramo, et al., 2006). In our both experiments, DO concentrations were within the suitable range.

An increase in the net cage area through the addition of substrate showed a significant increase in the final length and the weight of prawn PL compared to the control group (without substrate). Different studies have also reported that the addition of substrate improved growth, survival, FCR of $M$. rosenbergii compared to those reared without substrate (Cohen and Ra'anan, 1983; Marlowe, 2006; Simpson et al., 2016; Tidwell et al., 1998; Tuly et al., 2014). For example:
Mamun et al. (2010) reported that the addition of high-density polyethylene net substrate in $M$. rosenbergii nursing aquaria increased the final weight up to $32.70 \%$ compared to no substrate added aquaria. Also, an increase in growth, SGR, FCR, and survival might be attributable to less aggressive interactions and stress (Karplus et al., 1992).

In the present study, substrate placement created different layers inside a net cage based on the area increment (3 layers for $75 \%$ area increment, and two layers for $50 \%$ area increment). Hence, it might have created multiple layers of feeding spots with less conspecific interactions. Nevertheless, these substrates help them seek shelter on different net cage layers, providing them with a threedimensional area to utilize. That might be why $75 \%$ area increment group showed better growth and survival rate than any other treatments.

Periphyton that grew on the net cage's surface and the substrates might have played a vital role in the present study. Tuly et al. (2014) suggested that addition of substrate might help improving periphyton and natural food production for $M$. rosenbergii. In our experiments, periphyton biomass showed a decreasing trend throughout the experimental period. However, there was no significant difference $(\mathrm{p}>0.05)$ among the treatments (Fig. 1 and Fig. 2). The decreasing concentration of periphyton might due to an increased and efficient grazing on periphyton by the prawn PL. Prawn PL has an extra advantage over adult prawns, which is its smaller chelipeds. These smaller chelipeds might have helped them selectively graze on periphytic biomass. Tidwell et al. (1997) reported that small prawn 
utilizes natural foods more efficiently than prawn of large average size. The overall FCR was better in experiment 2 , and a significantly lower FCR was found in the treatment with sloping substrate (Table 4). Improvements in FCR due to substrate addition have been reported elsewhere (Tidwell et al., 2000; Tuly et al., 2014). It indicates that the addition of substrate in the prawn nursery unit could be beneficial. However, the proportionate increase in surface area and orientation might significantly affect improved growth, FCR and prawn PL survival rate.

The growth, FCR, SGR, and survival rate in the horizontally placed substrate group was consistent with $75 \%$ area increment treatment (Table 2). Vertically placed substrate group showed overall lower growth, SGR, and survival rate than the horizontal and sloping substrate group (Table 4). It might be because the prawn PL could not utilize vertically placed substrate efficiently for shelter or physical isolation from other individuals resulting in frequent agonistic interactions and stress. Hence, prawn PL might have shown lower growth as well as the survival rate of prawn PL. Secondly, the feed might have sunk to the bottom of the net directly, leading to increased feed wastage in vertically placed substrate treatment. Soft-shell prawns might not be efficient to utilize vertically installed substrate and are incredibly vulnerable to cannibalism and predation (Peebles, 1978; Smith and Sandifer, 1975).

However, no significant difference in growth, FCR, and survival rate of the prawn was found between horizontally or vertically placed substrate by Tidwell et al. (2002). In the present study, the significant differences in growth and FCR in the sloping substrate prawn group might be that the sloping substrates facilitated prawns to feed and graze efficiently compared to horizontal and vertical oriented substrates.

\section{Conclusion}

The results of experiment 1 showed that $75 \%$ area increment improved the growth, FCR, and survival of prawn PL. Keeping the area increment at $75 \%$, the sloping substrate group showed similar growth performance compared with horizontal substrate group and higher FCR compared to both horizontally and vertically placed substrate. Therefore, $75 \%$ area increment with the sloping substrate may be recommended for prawn PL nursing in cages. Further studies for evaluating the appropriate stocking density of prawn PL to get maximum growth, FCR and survival rate may be carried out.

\section{Acknowledgements}

The authors would like to thank the Research Management Wing (RMW) of BSMRAU for the financial and logistical support to conduct the experiments.

\section{References}

Abramo, L. R. D., J. H. Tidwell, M. Fondren and C. L. Ohs. 2006. Pond Production of the Freshwater Prawn in Temperate Climates. SRAC Publication 484 P.

Azim, M. E., M. A. Wahab, A. A. Van Dam, M. C. M. Beveridge, A. Milstein and M. C. J. Verdegem. 2001. Optimization of fertilization rate for maximizing periphyton production on artificial substrates and the implication of periphyton-based aquaculture. Aquacult. Res. 32: 749-760. 
Alam, M. J., M. E. Hoq and M. A. Mazid. 1997. Nursery rearing of Macrobrachium rosenbergii (de Man) using hapa-nets : effects of stocking density. Bangladesh J. Fish. Res. 1: 9-16.

Alston, D. E. 1989. Macrobrachium culture: a Caribbean perspective. World Aquacult. 201: 19-23.

Beveridge, M. C. M. 2004. Cage aquaculture. (3th ed.) Wiley-Blackwell, USA.

Boyd, C. and S. Zimmermann. 2010. Growout systems-water quality and soil management. Pp. 239-255. In M. N. K. (ed.), M. B. New, W. C. Valenti, J. H. Tidwell, L. R. D' Abramo (ed.). Freshwater Prawns Biology and Farming. Wiley Online Library.

Carvalho-Filho, J. and M. A. Mathias. 1998. Culture of larvae in closed static systems. Pp. 95-113. In Freshwater Crustaceans Culture Technology for Shrimp Production. Brasilia, Brazil.

Chen, S. M. and J. C. Chen. 2003. Effects of pH on survival, growth, molting and feeding of giant freshwater prawn Macrobrachium rosenbergii. Aquacult. 218: 613-623.

Cohen, D. and Z. Ra'anan. 1983. The production of the freshwater prawn Macrobrachium rosenbergii in Israel: III. Density effect of all-male Tilapia hybrids on prawn yield characters in polyculture. Aquacult. 35: $57-71$.

Cohen, D., Z. Raanan and T. Brody. 1981. Population profile development and morphotypic differentiation in the giant freshwater prawn Macrobrachium rosenbergii (de Man). J. World Maricult. Soc. 12: 231-243.

Cuvin-Aralar, M. L. A., A. G. Lazartigue and E. V. Aralar. 2013. Net mesh size affects production of giant freshwater prawn Macrobrachium rosenbergii cultured in lake-based cages. J. Appl. Ichthyo. 29: 833-838.
D’Abramo, L. R., J. M. Heinen, H. R. Robinette and J. S. Collins. 1989. Production of the freshwater prawn Macrobrachium rosenbergii stocked as juveniles at different densities in temperate zone ponds. J. World Aquacult. Soc. 20: 81-89.

D’Abramo, L. R., J. H. Tidwell, M. W. Fondren and C. L. Ohs. 2006. Pond production of the freshwater prawn in temperate climates. SARC Publication 484 P.

DoF (Department ofFisheries). 2018. Compendium of Fish Week 2018. Department of Fisheries, Ministry of Fisheries and Livestock, Dhaka.

Karplus, I., G. Hulata and S. Zafrir. 1992. Social control of growth in Macrobrachium rosenbergii IV. The mechanism of growth suppression in runts. Aquacult. 106: 275-283.

Krzywinski, M., N. Altman and P. Blainey. 2014. Nested designs. Nat Methods. 11: 977-978.

Kiyohara, F. 2006. Cultivo de Macrobrachium amazonicum (Heller, 1862) em cerrados e em tanques-rede durante a fase de berçários e a fase de crescimento final e cultivo de Macrobrachium potiuna (Müller, 1880) em laboratório (Crustacea, Decapoda, Palaemonidae). Universidade de São Paulo (USP), Instituto de Biociências.

Ling, S. W. 1969. Methods of rearing and culturing Macrobrachium rosenbergii. FAO Fish. 3: 57.

Mamun, M. A. A., M. A. Hossain, M. S. Hossain and M. L. Ali. 2010. Effects of different types of artificial substrates on nursery production of freshwater prawn, Macrobrachium rosenbergii (de Man) in recirculatory system. J. Bangladesh Agricul. Univ. 8: 333-340.

Marcus, E. L. 2002. The effects of substrate orientation and colour on survival and growth of freshwater prawn $M$. rosenbergii. M.S. Thesis, University of Tennessee, Knoxville, United States.

Marlowe, H. A. 2006. The Effects of Nursery Length and Pond Substrate Use in Production of Freshwater Prawn 
Macrobrachium rosenbergii. University of Tennessee, Knoxville, United States.

New, M. B. and S. Singholka. 1985. Freshwater prawn farming. A manual for the culture of Macrobrachium rosenbergii. Rev. FAO Fisheries Technical Paper (FAO). 1: 225.

New, Michael. B. 1990. Freshwater prawn culture: a review. Aquacult. 88: 99-143.

Peebles, B. 1978. Molting and mortality in Macrobrachium rosenbergii. Proceed. Ann. Meet. W. Mari. Soc. 9: 39-46.

Smith, T. J. and P.A. Sandifer. 1975. Increased production of tank-reared Macrobrachium rosenbergii through use of artificial substrates. Proceed. Ann. Meet. World Mari. Soc. 6: 55-61.

Simpson, S. D., A. N. Radford, S. L. Nedelec, M. C. O. Ferrari, D. P. Chivers, M. L. McCormick and M. G. Meekan. 2016. Anthropogenic noise increases fish mortality by predation. Nat. Communicat. 7: 10544

Srinivas, D. and C. Venkatrayalu. 2016. Studies on present problems and prospects of shrimp farming in west Godavari district of Andhra Pradesh, India. Advan. Appl. Sci. Res. 72: 49-54.

Tidwell, J. H., S. Coyle, C. D. Webster, J. D. Sedlacek, P. A. Weston, W. L. Knight and M. J. Fuller. 1997. Relative prawn production and benthic macroinvertebrate densities in unfed, organically fertilized, and fed pond systems. Aquacult. 149: 227-242.
Tidwell, J. H., S. D. Coyle and G. Schulmeister. 1998. Effects of added substrate on the production and population characteristics of freshwater prawns Macrobrachium rosenbergii in ponds. J. World Aquacult. Soc. 29: 17-22.

Tidwell, J. H., S. D. Coyle, A. VanArnum, C. Weibel and S. Harkins. 2000. Growth, survival, and body Composition of cage-cultured Nile Tilapia Oreochromis niloticus fed pelleted and unpelleted distillers grains with solubles in polyculture with freshwater prawn Macrobrachium rosenbergii. J. World Aquacult. Soc. 31: 627-631.

Tidwell, J. H., S. D. Coyle, A. Arnum, and C. Weibel. 2002. Effects of substrate amount and orientation on production and population structure of freshwater prawn Macrobrachium rosenbergii in ponds. $J$. World Aquacult. Soc. 33: 63-69.

Tuly, D. M., M. S. Islam, M. Hasnahena, M. R. Hasan and M. T. Hasan. 2014. Use of artificial substrate in pond culture of freshwater prawn (Macrobrachium rosenbergii): a new approach regarding growth performance and economic return. J. Fish. 2: 53-58.

Willis, S. A. and M. E. Berrigan. 1976. Growout of the Giant Malaysian prawn, Macrobrachium rosenbergii in earthen ponds in Central Florida. Job Completion Report for NOAA, NMFS, PL88. 